\title{
The Use of Twitter in Large Lecture Courses: Do the Students See a Benefit?
}

\author{
Heather M. Ross, Ryan Banow \& Stan Yu \\ University of Saskatchewan, Canada
}

\begin{abstract}
The purpose of this two-year quantitative study was to determine the usefulness of the micro-blogging tool Twitter in large classes for improving the students' sense of community and belonging. Three instructors of large classes were recruited to test the outcomes of using Twitter as a learning tool, one each from the Departments of Geography and Psychology, and the College of Nursing. Twitter was used as a learning tool to allow students to engage in discussion and ask questions in real time during class as well as outside of class. The method used by the authors included surveys that measured students' perception of their sense of community and belonging, their engagement with the Twitter portion of the course, and their thoughts on the use of Twitter for academic purposes in a higher-education classroom setting. Data about students' use of Twitter was further collected using the Twitter Archiving Google Spreadsheet tool. The authors conclude this study showed that Twitter, if integrated into the course and supported by instructor and/or assistants who are familiar with the use of Twitter, improved the sense of community reported by students.
\end{abstract}

Keywords: Microblogging; Twitter; Learning technologies; Community; Large classes; Higher education

\section{Introduction}

Researchers from a Canadian research-intensive university's teaching and learning center conducted a two-year study involving the use of social networking tool Twitter in an effort to determine if the microblogging platform would be useful in helping students in large lecture courses feel more connected and less isolated. Twitter was integrated for academic purposes in a total of six course sections, each with enrolments of more than 100 students, in three disciplines throughout the study.

Large lecture classes with their crowded rows of students can make it difficult for both instructors and students to get to know everyone's name, let alone feel a sense of connection with others. It can be a challenge to convince students to ask questions or give opinions and can be difficult for students to engage in discussions with their fellow classmates, which can lead to students feeling a sense of isolation (Geske, 1992; Baldwin \& Koh, 2012).

As Rovai and Jordan (2004) noted, the literature supports the need for a sense of community in higher education classes to alleviate students' feelings of isolation. Rovai (2002) argued that 
classroom community has "two components: feelings of connectedness among community members and commonality of learning expectations and goals." (p. 322) Elements of community, according to Selznik (1996) include: historicity, identity, mutuality, plurality, autonomy, participation and integration. Many, if not all of these elements can be fostered in learning environments.

In their research, Freeman, Anderman, and Jensen (2007) found that students' self-reported sense of belonging in university level courses was connected to motivation for academic success in class. McKinney, McKinney, Franiuk, and Schweitzer (2006) noted that their research and the literature supports the premise that a perceived sense of community is linked not only with a students perceived motivation for academic success, but with actual academic success.

In Seven Principles for Good Practice in Undergraduate Education, Chickering and Gamson (1987) provides general recommendations that could assist in building a sense of community, including encouraging contact between students and faculty, developing reciprocity and cooperation among students, using active learning techniques, giving prompt feedback and respecting diverse talents and ways of learning. Nevertheless, achieving these recommendations in larger classes can be difficult.

\section{Twitter}

Microblogging refers to the use of technologies to write short messages that are usually available for viewing by the general population. Twitter, currently the most recognized micro-blogging tool, allows for users to post messages, called "tweets" of up to 140 characters in length, including links to other online resources. Twitter users can follow, reply, private message, or re-publish each other's posts (known as "retweeting") creating communication opportunities not just with those they follow and are followed by, but also the people in the Twitter networks of those users (Gao, Luo, \& Zhang, 2012). Users can access their accounts through the Twitter website or by using applications on a computer or mobile device.

Twitter is frequently used at academic conferences, with a conference hashtag being established by the conference organizers or attendees. Attendees and others following the hashtag can engage in conversation, share resources or simply follow the happenings at the conference. The use of Twitter for such event specific communication is often referred to as a "backchannel".

Many of the recommendations that Chickering and Gameson (1987) listed can be accomplished or at least aided by the integration of certain types of learning technologies including Twitter. Scholars, including Drexler, Baralt, and Dawson (2008) have argued for the integration for such purposes and there is a growing body of literature supporting the use of microblogging tools in face-to-face higher education courses. Junco, Heiberger, and Loken (2011) found that the integration of microblogging tools in higher education classes increased student engagement. In an analysis of existing studies, Gao, Luo, and Zhang (2012) found that the use of Twitter in courses may also help build connections between students and other students (as well as instructors). Further, those connections may persist beyond the duration of the class, though they did note that 
"the differences among the identified studies in terms of settings, sample size, duration and quality," made the results of the overall analysis inconclusive (Gao et al., 2012, p. 794).

There are a number of benefits to the use of a Twitter backchannel compared to more prevalent learning technologies such as email or discussion forums. Ross (2013) discussed how the brevity, timeliness, and openness of Twitter provide opportunities for use in ways not possible with many other learning technologies. For example, while students can answer each other's questions through email or discussion forums, this is not ideal for quick questions such as where a particular lab might be located or if students have resources to share with the rest of their class. More open methods of communication such as microblogging allow former students to connect, advise and answer questions. This is not possible using the communication tools in most learning management systems (LMS), such as Blackboard, since generally institutions only allow current students into course sections on the institution's LMS. These open methods also allow "experts" in the discipline being studied to enter conversations much like the potential former students. Students are able to see real-life examples of the topics, issues and events being covered in class. For example, students in a first-year political studies course can follow news coverage and candidates during an election cycle.

As Tess (2013) noted, the research on the effectiveness of the integration of microblogging tools into higher education for increasing student engagement and developing a sense of community is inconclusive. There are also questions about whether students will want to use Twitter as part of a class. McNeil (2010) found that students were more interested in using social networking tools like Facebook, over Twitter because their friends and family were already on it, while Welch and Bonnan-White (2012) found that students may suffer from "log-in overload" because of the number of online sites and tools (i.e. the LMS, email and Twitter) they may need to access for a class.

The researchers involved in the study documented in this paper were interested to see if the integration of Twitter for academic purposes in large lecture courses would help reduce student isolation and assist in developing a sense of community in those classes. The researchers also wanted to add to the existing body of literature by determining potential best practices for integration. This study examined the students' level of interest in using microblogging in large lecture courses and attempted to determine if such use increased students' self-reported sense of community and sense of belonging.

\section{Participants}

Methodology

The study began with an attempt to recruit at least one instructor who was teaching two sections of a large first-year lecture course. The researchers, who were all on staff at the university's teaching and learning center, hoped to conduct the study with one section including the integration of Twitter while the other served as a control group. The researchers approached a number of instructors on campus who were teaching classes with maximum enrolments of more than 100 students. Of those interested, none were teaching more than one section of the same course within a single term. In the end, three instructors were recruited based on the size and 
level of their courses, as well as their willingness to attempt to integrate Twitter into their courses and to have their courses be part of the research study. The courses included one section each of a Geography course, Psychology course, and Nursing course for each year of the study.

The Geography and Psychology courses were both first-year courses, but included students from a variety of majors and levels of their undergraduate work. The Nursing course, while a first-year course for that program, consisted of second-year university students due to a required preprogram year of prerequisites.

Each of the two sections of the Psychology course during the study had maximum enrolment caps of 350 students, while the Nursing course had spots for 125 students in each section and the Geography course 175 per section. All three instructors informed us that the sections were full at the start of the terms, which would result in 1,300 students who could have taken part in the study, but some students dropping out of these courses throughout the term would be normal.

The levels of experience with microblogging were varied among the instructors. The Psychology instructor had no prior experience with micro-blogging while the Geography instructor had a Twitter account, but had never sent a "tweet". The Nursing instructor, however, was active on Twitter and had already made use of it in teaching previous classes.

The instructors were offered assistance at the start of the study in multiple ways. The Psychology and Geography instructors were provided hands-on training on how to use Twitter. Accounts were created and hashtags (a word or words preceded by the "\#" symbol that individuals or groups can use to denote the topic of a conversation, such as the name of a conference) were established for both courses. The Psychology instructor chose a teaching assistant to act as the Twitter account moderator. The Nursing instructor acted as the moderator for her course Twitter account, which she set up herself. She required no assistance with using Twitter within her course. For the first term of the study, the Geography instructor received assistance from a former student who was a part of the peer assisted learning program at the university, but the instructor served as the moderator himself after that. The student moderators were provided the same hands-on training as the instructors.

Prior to the start of the first term of the study, the researchers submitted an application to and received approval from the Research Ethics Board for their research plan. The application for an exemption included copies of the proposed surveys, which included a cover page of information about the study and contact information for the researchers to be provided to the students in the courses within the study. Students were informed at the outset that completion of the survey and the use of Twitter for the course were both voluntary and that by completing the survey they were giving consent for the researchers to use their survey data in the study. They were then provided with links to online resources on how to use Twitter as well as information about the course Twitter account and hashtag.

At the start of each term, surveys were administered to the students in each of the three courses in which they were asked questions related to demographics, experience with microblogging and social media and their interest in the use of microblogging in education. Students were asked to indicate their gender and network services identification number (NSID), which is different than 
their student number. The question of gender was for demographics, while the researchers intended to use the student NSIDs on the pre-term and post-term surveys to determine changes in student attitudes and use of Twitter throughout the term. Several students used fake NSIDs, which lead the researchers to abandon this part of the analysis.

The researchers later decided that the information on the initial surveys would only be used for demographic purposes as students could not have formed enough of an opinion about the sense of community or belonging in the classroom on the first day. The researchers felt that the data derived from questions related to sense of community and belonging on that survey would not be useful for comparing to the end of term surveys.

Throughout the term, the public tweets of the course accounts and students either using the course hashtag or tweeting specifically to the course account were tabulated using the Twitter Archiving Google Spreadsheet (TAGS) tool. The purpose of this was to determine the amount of activity between the course account and students as well as between students who made use of the course hashtag.

Throughout the term the instructors used Twitter as a backchannel for communication between the instructor and students, students and students, and anyone else who cared to join the conversation. While none of the instructors viewed or displayed Twitter during class, students were allowed to tweet (electronic devices were allowed in all three courses). The instructors shared resources and other information such as reminders about upcoming assessments with students through Twitter, but in many instances, they also posted that same information through the University's LMS.

A meeting where initial results were shared was held with the researchers and instructors in the summer between the two years of data. The instructors also had a chance to discuss their own experiences. During the meeting some recommendations were made for changes to how Twitter was being used in the classes due to what appeared to be a lack of interest on the part of the students in using Twitter. The loss of a student assistant for the Geography course and unforeseen circumstance that kept the Nursing instructor away from class for a few weeks likely played a role in these new recommendations not being implemented to the extent they may have otherwise.

At the end of each term, surveys were again administered to students in each class. The questionnaire consisted of most of the same questions as those that appeared on the pre-term survey (the post-term surveys did not ask about gender) plus questions related to whether students felt comfortable asking questions and engaging in discussions with others in class, their sense of belonging both in class and at the university as a whole, their engagement with the Twitter portion of the course, and their thoughts on the use of Twitter for academic purposes in a higher-education classroom setting. Both surveys included closed and open-ended questions.

In the first year of the study, the pre-term surveys were almost all paper-based with a few completed electronically in the Psychology course, at the request of the instructor. The Psychology course ran in the term after the initial offering of the Geography and Nursing courses. Students were provided the link in class and had time with the instructor out of the room to complete the survey. They also received the link through an email from the instructor after class to provide 
those students who missed class, had no communications device with them in class, or experienced technical difficulties with another chance to complete the survey. The students were informed that the instructors would never have access to the paper or electronic surveys.

In the second year, the pre-term and post-term surveys were administered almost entirely electronically, with some paper copies provided to students upon request if they had no electronic devices, experienced technical difficulties or preferred a paper copy.

\section{Results}

\section{Response Rate}

The response rate for all classes on the pre-term survey was $68.5 \%$. Within our sample, there was a considerable skewing in terms of gender with $68.6 \%$ of students being female (Table 1 ). While these were all technically first-year courses, only $48.6 \%$ of students indicated that they were in the first year of their program, while $41.9 \%$ said that they were in the second year, $6.3 \%$ indicated third, $1.8 \%$ fourth, and $1.4 \%$ in their fifth year.

Table 1. Gender of Participants

\begin{tabular}{lll}
\hline & Male & Female \\
\hline Geography & $54.4 \%$ & $45.6 \%$ \\
\hline Nursing & $10 \%$ & $90 \%$ \\
\hline Psychology & $36.7 \%$ & 68.3 \\
\hline
\end{tabular}

\section{Student Use, Comfort and Expectations for Twitter at Start of Term}

As part of the pre-term survey, students were asked about their use and comfort level with Twitter and other social media tools. Students were asked "How comfortable are you with using social media (e.g. Websites like Facebook, Twitter, LinkedIn)?" and asked to provide an answer on a sixpoint Likert scale ranging from "Very Uncomfortable" to "Very Comfortable". A total of 889 students responded to this question with $62.6 \%$ of the students answering that they were "comfortable" or "very comfortable" using social media (Table 2 ).

Table 2. Comfort Level with Social Media

\begin{tabular}{ll}
\hline Response (point on scale) & Frequency \\
\hline Very Uncomfortable (1) & $13.6 \%$ \\
\hline Uncomfortable (2) & $2.8 \%$ \\
\hline Somewhat Uncomfortable (3) & $5.6 \%$ \\
\hline Somewhat Comfortable (4) & $15.3 \%$ \\
\hline Comfortable (5) & $44.3 \%$ \\
\hline Very Comfortable (6) & $18.3 \%$ \\
\hline
\end{tabular}


Students were also asked about the frequency of their use of social media in their day-to-day lives. They were asked to place the frequency of their use on a seven-point scale that ranged from "Never" to "Every Hour". Of the 890 responses to this question, $77.8 \%$ indicated that they were using social media at least once daily (Table 3 ).

Table 3. Frequency of Social Media Use

\begin{tabular}{ll}
\hline Response (point on scale) & Frequency \\
\hline Never (1) & $5.5 \%$ \\
\hline Monthly (2) & $2.8 \%$ \\
\hline Weekly (3) & $4.4 \%$ \\
\hline A few times a week (4) & $10.7 \%$ \\
\hline Every day (5) & $29.3 \%$ \\
\hline A few times a day (6) & $34.6 \%$ \\
\hline Every hour (7) & $13.8 \%$ \\
\hline
\end{tabular}

The students were then asked specifically about their use of Twitter. The first question about Twitter asked if students had Twitter accounts, with 486, or $55.7 \%$ answering "yes" ( 873 students answered this question). The next question asked about the frequency of their use of Twitter. While only 486 students had answered the previous question in the affirmative, 491 answered the follow up question about their frequency of using Twitter. This question asked students to rate the frequency of their Twitter use on a seven-point scale ranging from "Never" to "Every Hour". Of the students who answered this question $42.5 \%$ indicated that they used it at least daily (Table 4).

Table 4. Frequency of Twitter Use

\begin{tabular}{lc}
\hline Response & Frequency \\
\hline Never (1) & $16.5 \%$ \\
\hline Monthly (2) & $13.4 \%$ \\
\hline Weekly (3) & $9.8 \%$ \\
\hline A Few Times Per Week (4) & $15.7 \%$ \\
\hline Every Day (5) & $18.7 \%$ \\
\hline A Few Times a Day (6) & $18.3 \%$ \\
\hline Every Hour (7) & $5.5 \%$ \\
\hline
\end{tabular}

Finally, students were asked if they would be interested in using Twitter as part of their class, with $70 \%$ indicated that they would.

\section{Post-Term Survey Response Rate}

Overall, between the two years of data collection, 666 students completed the post-term survey, which represents $51.2 \%$ of the students registered in the participating classes at the start of the terms. 


\section{Student Participation in Twitter Portion of Course}

Students were asked on the post-term survey if they had participated in the Twitter portion of the course throughout the term. Of the 595 students who answered this question over the two years of the study, $45 \%$ answered "yes". The responses by course and year of the study are shown in Table 5.

Table 5. Student Participation in Twitter Portion of Course

\begin{tabular}{lll}
\hline Course and Year & $\begin{array}{l}\text { Percentage of Course } \\
\text { Enrollment - Yes }\end{array}$ & $\begin{array}{l}\text { Percentage of Course } \\
\text { Enrollment - No }\end{array}$ \\
\hline Geography Year 1 & $35.5 \%$ & $64.5 \%$ \\
\hline Geography Year 2 & $34.5 \%$ & $65.5 \%$ \\
\hline Nursing Year 1 & $57.8 \%$ & $42.2 \%$ \\
\hline Nursing Year 2 & $57.8 \%$ & $42.2 \%$ \\
\hline Psychology Year 1 & $51.6 \%$ & $48.4 \%$ \\
\hline Psychology Year 2 & $47.2 \%$ & $58.8 \%$ \\
\hline
\end{tabular}

The actual number of students who tweeted to the course accounts or used the course hashtags in these courses was quite low compared to the number who indicated that they had participated. For example, less than a third of the students in either section of the Nursing course sent any tweets to the course account or using the course hashtag (Table 6), while roughly twice that number reported that they had participated. As shown in Table 6, the number of tweets sent per tweeting student varied by course, with most sections of the courses having an average of 1.5 to 2.6 tweets per student. The first year of the Geography course was the exception with an average of 10.5 due to two students being very active on Twitter.

Table 6. Number of Students Who Tweeted and Tweets Per Student Averages

\begin{tabular}{lll}
\hline Course and Year & $\begin{array}{l}\text { Percentage of Course } \\
\text { Enrolment }\end{array}$ & $\begin{array}{l}\text { Tweets Sent Per Student } \\
\text { Tweeter }\end{array}$ \\
\hline Geography Year 1 & $39(23.9 \%)$ & 10.5 \\
\hline Geography Year 2 & $44(25.9 \%)$ & 1.5 \\
\hline Nursing Year 1 & $22(17.6 \%)$ & 2.1 \\
\hline Nursing Year 2 & $34(27.2 \%)$ & 2.2 \\
\hline Psychology Year 1 & $52(17.3 \%)$ & 1.7 \\
\hline Psychology Year 2 & $43(14.3 \%)$ & 2.6 \\
\hline
\end{tabular}

\section{Student Views on the Use of Twitter in Lecture Courses}

The researchers also were interested in the students' views on the use of Twitter in lecture courses. Students were asked if they would recommend using Twitter as a backchannel (a means 
of communicating about the course both inside class during lectures and discussion that also has the ability to continue outside of class) for post-secondary classes. Overall, $36.6 \%$ of students indicated that they would recommend it while $23.6 \%$ said that they would not, and $39.8 \%$ were undecided.

In addition, the researchers looked to see if there was a difference between those who had participated in the Twitter portion of the course and those who had not. Of those who had participated, 59.4\% said they would recommend the use of Twitter as a backchannel for postsecondary classes, $11.8 \%$ said they would not and $28.7 \%$ said they were undecided. Of those who had indicated that they had not taken part in the Twitter portion of the course, 18.3\% said "yes", $33.1 \%$ said, "no" and $48.6 \%$ were undecided.

The students were given the opportunity to provide their views on why they would or would not recommend the use of Twitter in post-secondary classes in the form of an open-ended question. An initial review of this data revealed some recurring themes:

- Students did not like having to check multiple places (i.e. Twitter, email and Blackboard) for information from the instructor.

- Students saw Twitter as a tool for social interactions, but did not see its relevance to the class.

- Some students did like having a place to go for quick information such as whether class was cancelled.

- A few of the student comments indicated that they saw a usefulness for Twitter in postsecondary, but that they did not like how it was used in their particular class.

The researchers also wanted to know whether the students who had indicated that they had not taken part in the Twitter portion of the course declined to participate due to the public nature of Twitter. These students were asked “Would you have been more likely to use Twitter if it wasn't public?" Only $17.9 \%$ of students said "yes" to this question with $82.1 \%$ saying "no" (undecided was not an option).

\section{Twitter Integration Effect on Student Sense of Community and Belonging}

The researchers were interested in whether the integration of Twitter in the lecture courses would have any effect on the students' sense of community and sense of belonging in large courses.

Students were asked a set of questions aimed at measuring different facets of classroom community. Each item was asked on a six-point Likert scale, ranging from "strongly disagree" to "strongly agree". Mann-Whitney U Tests were used to determine whether differences existed between those who indicated they had participated in the Twitter portion of the course and those who had not. As shown in Table 7, it was uncovered that students who participated in the Twitter portion of the course were significantly more likely to perceive that it is easy to find support from other students outside of class $(U=39277.5, z=-2.10, p=0.04)$ and feel that they are encouraged to find and share educational resources with others when compared to students who had not participated in the Twitter portion of the course $(U=36969.5, z=-3.17, p=0.002)$. Moreover, 
students who had participated in the Twitter portion of the course were significantly more likely to agree that there is a sense of community amongst students and the instructors in the course than those who had not $(U=36414.5, z=-3.32, p=0.001)$. Finally, when asked if students felt it is easy to get help when they have a question in the course, minimal differences were found between the two groups.

Table 7. Sense of Community

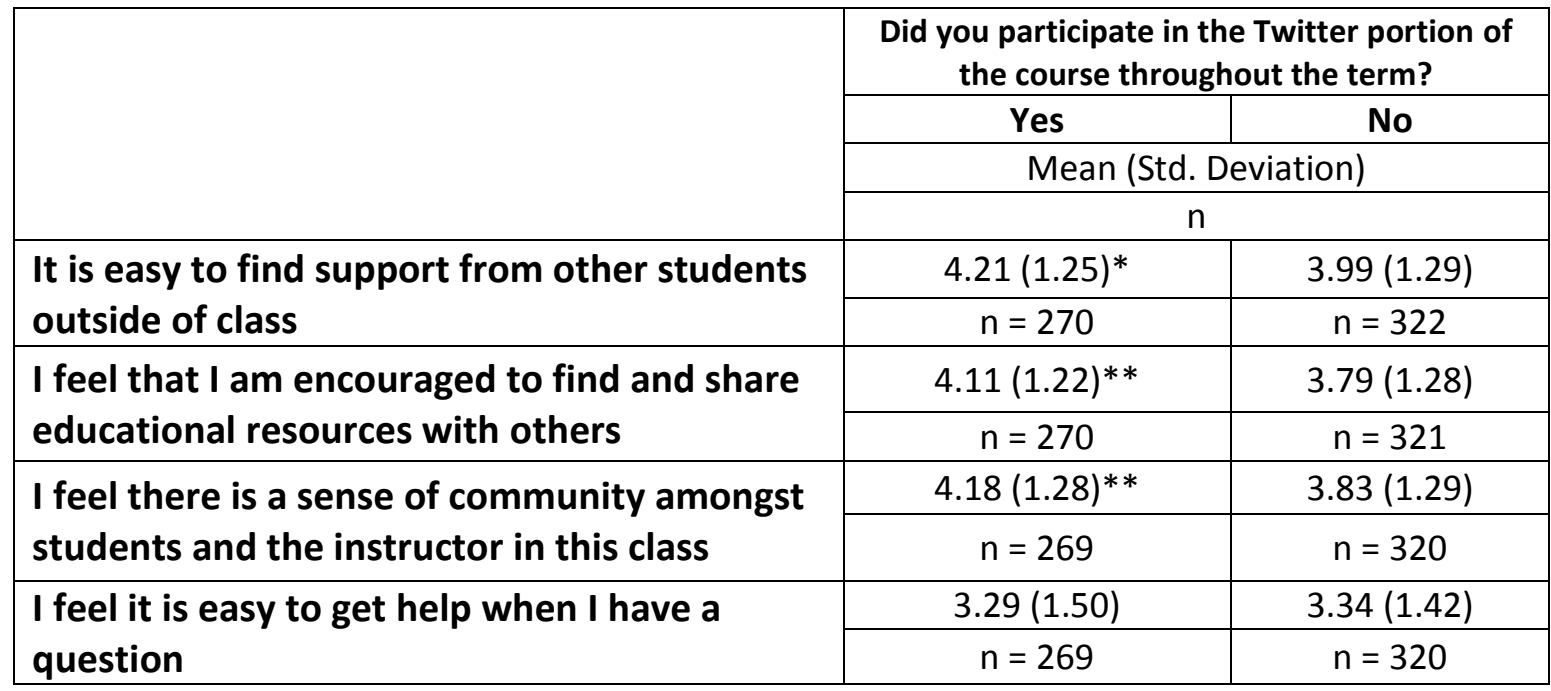

${ }^{*}$ significant at $0.05{ }^{* *}$ significant at $0.01 ;{ }^{* * *}$ significant at 0.001

The researchers also gauged the students' perceived sense of belonging with other students in their course, the course overall, and within the University at large. Using a five-point Likert scale, possible answers consisted:

- I feel strongly connected

- I feel comfortable

- I feel a little apprehensive but hope to fit in soon

- I feel like I am just an anonymous student

- I feel like nobody knows me or cares about me

It is important to note that, as enumerated above, this particular scale was scored inversely. In turn, the data was analyzed using Mann-Whitney $U$ Tests to determine if there were differences between those who took part in the Twitter portion of the course and those who did not. Table 8 reveals that, while students who had participated in the Twitter portion of the course were found to be slightly more likely to feel a sense of belonging in all three categories compared to those who had not participated, the differences between the two groups were marginal and not statistically significant. 
Table 8. Sense of Belonging

\begin{tabular}{|l|c|c|}
\hline \multirow{2}{*}{} & \multicolumn{2}{|c|}{$\begin{array}{c}\text { Did you participate in the Twitter portion of } \\
\text { the course throughout the term? }\end{array}$} \\
\cline { 2 - 3 } & Yes & No \\
\cline { 2 - 3 } & \multicolumn{2}{|c|}{ Mean (Std. Deviation) } \\
\cline { 2 - 3 } & \multicolumn{2}{|c|}{$\mathrm{n}$} \\
\hline \multirow{2}{*}{$\begin{array}{l}\text { Which statement best describes your feeling of } \\
\text { belonging with other students in your class? }\end{array}$} & $2.72(1.10)$ & $2.8(1.06)$ \\
\hline \multirow{2}{*}{$\begin{array}{l}\text { Which statement best describes your feeling of } \\
\text { belonging within your class? }\end{array}$} & $2.63(1.06)$ & $\mathrm{n}=318$ \\
\hline \multirow{2}{*}{$\begin{array}{l}\text { Which statement best describes your feeling of } \\
\text { belonging within the University? }\end{array}$} & $2.38(1.03)$ & $2.78(1.06)$ \\
\cline { 2 - 3 } & $\mathrm{n}=268$ & $\mathrm{n}=320$ \\
\hline
\end{tabular}

${ }^{*}$ significant at $0.05 ;{ }^{* *}$ significant at $0.01 ;{ }^{* * *}$ significant at 0.001

\section{Limitations}

There are a number of limitations to this study. The researchers may have been better served by using existing methods of measuring sense of community, namely the Classroom Community Scale (CCS) developed by Rovai and Jordan (2004). Relying on participants to define "community" and "belonging" calls into question the validity of the data. The fact that the questions on the surveys changed between the two years of the study makes it even less likely that the data around those questions can be trusted.

After the first year of the study and initial analysis of results, the researchers made changes to some of the survey questions, as well as adding some additional questions to the survey. Following the analysis of the data after the second year of the study, the researchers viewed the wording of some of the questions, including the differences in scales as problematic. There were several different scales included with a variety of wording and scale size. The changes to the survey questions may have led to confusion on the part of the students and complicated the analysis of the data. The survey should be redeveloped for any future studies on this topic.

The response rate was moderately higher when paper-based surveys were administered in class than when electronic administration of the surveys was used. The change came after a request from one of the instructors. The researchers agreed as both a method of cost-savings and for environmental reasons as well as saving time in the administration (handing out and collecting 
surveys from the students in class) and input of the data (typing the data into the survey tool). While there were paper copies of the surveys offered to the students, the move to mainly electronic surveys may have resulted in not reaching some of the students without laptops, smart phones or tablets or those uncomfortable with technology or preferring not to answer online.

Finally, the researchers should have asked students to indicate their gender on the post-term surveys as they did on the pre-term surveys to help determine how representative a sample there was for the post-term surveys.

\section{Discussion}

The researchers relied on participants to self-report on their "sense of community" and "sense of belonging". While the students who took part in the Twitter portion of the course did report a higher "sense of community", there was little difference in terms of "sense of engagement". Further research into this area using a validated scale such as the CCS developed by Rovai and Jordan would be prudent to better understand if Twitter has any impact on these elements in large lecture courses.

Based on the research in this study, it is not possible to determine whether the use of Twitter added to the sense of community and sense of engagement or those who perceived a sense of community and a sense of engagement were more like to use Twitter because of the nature of their personalities. This is an area that may warrant further research.

The students in the courses in this study seemed disinterested in making use of Twitter as a backchannel in higher education, though they did not dismiss the notion outright. While $45 \%$ of participants said that they participated in the Twitter portion of the course, the lack of tweets students sent to the course account or use of the corresponding hashtags, leads the researchers to question whether the students overestimated their own participation or defined their participation broadly to include simply reading some of the tweets. The increase in participation from $17.6 \%$ of students in year 1 of the Nursing course to $27.2 \%$ in year 2 may be a result of the Nursing instructor limiting the sharing of some information to Twitter instead of reposting it in the LMS. Based on the data, the public nature of Twitter did not play a role in the lack of Twitter use amongst the students.

While only $36.6 \%$ of the participants would recommend the use of Twitter as a backchannel in post-secondary classes, $39.8 \%$, the largest single block, were undecided. This may mean that the students see a potential for the user of Twitter for academic purposes, but did not see enough value in the way it was used in this study. This is another area that should be researched more thoroughly to determine if microblogging in general (or social media overall) and Twitter more specifically is something that students see a value in being integrated into their learning.

Overall, the lack of student interest in using Twitter is in line with what McNeil (2010) found and could be linked to the "log-in overload" phenomenon that Welch and Bonnan-White (2012) noted or simply a general dislike of this particular tool. 


\section{Conclusion}

Despite the issues detailed in the Limitations section of this paper, the research appears to show similar results as others have previously noted when looking at both small and larger lecture courses, including student interest in using Twitter in class (Welch \& Bonnan-White, 2012; Lin et al., 2013). While students in our study did not appear to be interested in using the tool for learning in these specific courses, they did show some openness to potential uses in postsecondary education. This indicates further research into best practices for Twitter integration is warranted. In addition, the increase in sense of community among those students who did take part in the Twitter portion of the classes is promising.

\section{References}

Chickering, A. W. \& Gamson, Z. F. (1987). Seven principles of good practice. AAHE Bulletin, 39 3-7.

Drexler, W., Baralt, A., \& Dawson, K. (2008). The Teach Web 2.0 Consortium: A tool to promote educational networking and Web 2.0 use among educators. Educational Media International, 45(4), 271-283.

Freeman, R. M., Anderman, L. H., \& Jensen, J. M. (2007). Sense of belonging in college freshmen at the classroom and campus levels. The Journal of Experimental Education, 75(3), 203-220.

Gao, F., Luo, T., \& Zhang, K. (2012). Tweeting for learning: A critical analysis of research on microblogging in education published in 2008-2011. British Journal of Educational Technology, 43(5), 783-801.

Geske, J. (1992). Overcoming the drawbacks of the large lecture class. College Teaching. 40(4), 151-154.

Junco, R., Heiberger, G., \& Loken, E. (2011). The effect of Twitter on college student engagement and grades. Journal of Computer Assisted Learning, 27(2), 119-132.

Lin, M. G., Hoffman, E. S., \& Borengasser, C. (2013). Is social media too social for class: A case study of Twitter use. Tech Trends. 57(2), 39-45.

McKinney, J. P., McKinney, K.G., Franiuk, R., \& Schweitzer, J. (2006). The college classroom as a community: Impact on student attitudes and learning. College Teaching, 54(3). P. 281-284.

McNeill, T. (2010). Much ado about Twitter: Using Twitter for a final-year Shakespeare course. Proceedings of the INTED2010 Conference (pp. 5784-5789). Valencia, Spain.

Ross, H. M. (2013, June 24). Why twitter and not email [Web log post]. Retrieved on 5 February 2015 from http://www.mctoonish.com/blog/?p=1314

Rovai, A. P. (2002). Sense of community, perceived cognitive learning, and persistence in asynchronous learning networks. The Internet and Higher Education. 5, 139-332. 
Rovai, A. P. \& Jordan, H. M. (2004). Blended learning and sense of community: A comparative analysis with traditional and fully online graduate courses. International Review of Research in Open and Distance Learning. 5(2), 1-13.

Selznik, P. (1996). In search of community. In W. Vitek \& W. Jackson (Eds.), Rooted in the land: Essays on community and place (pp. 195-203). New Haven: Yale University Press.

Tess, P. A. (2013). The role of social media in higher education classes (real and virtual) - A literature review. Computers in Human Behaviour. 29, 60-68.

Welch, B. K. \& Bonnan-White, J. (2012). Twittering to increase student engagement in the university classroom. Knowledge Management \& E-Learning: An International Journal, 4(3), 325-345.

Correspondence: Heather M. Ross, Instructional Design Specialist, The Gwenna Moss Centre for Teaching Effectiveness, University of Saskatchewan, Saskatoon, Saskatchewan, Canada 